\title{
Impacts of wildlife trade and sustainable development in Vietnam
}

\author{
Duc Hanh Nguyen ${ }^{1 *}$ and Thi Mai Dinh ${ }^{2}$ \\ ${ }^{1}$ Hanoi Procurotarote University, Duong Noi Street, Hanoi, Viet Nam \\ ${ }^{2}$ Graduate Academy of Social Science (GASS), 477 Nguyen Trai Street, Hanoi, Viet Nam
}

\begin{abstract}
Viet Nam harbors a high level of biological diversity in the world. However, Viet Nam is also known as one of the countries having a high demand of biological resource use in Asia. The illegal trade and consumption of wildlife products have become a major threat to the biodiversity. The consequences of unsustainable use in recent decades have led to a rapid population decline many animal and plant species particularly endangered species and many species are now facing extinction. A total of 179 species of animals and 94 species of plants was listed in the governmental decree as endangered and with a high priority of conservation concern.. A number of large mammals or flagship species have become extinct or their populations have been severely declined due to overexploitation and illegal collecting, for example: Javan Rhinoceros (extinct), Indochinese Tiger, Gray Gaur, Wild Buffalo, Golden Deer, and Eld's Deer. Viet Nam has also known as an important hub and hotspot in Southeast Asia for the consumption of plant and wildlife products, and transit point for the illegal wildlife trade in Asia. Thousands of wildlife animals (more than 20,000 tons per year) have been exploited and consumed for traditional medicine or trade purposes in Viet Nam. This article focuses on the challenges of prosecution and crimes relating to wildlife trade in Viet Nam. It also provides an analytical framework for assessing the impact of wildlife trade and criminal status relating to wildlife in Viet Nam on conservation and local livelihoods.
\end{abstract}

\section{Introduction}

Wildlife trafficking is also a net loss of revenue for the affected countries, as it evades taxes, trade levies, and negatively affects tourism and ecosystem services provision (Rosen $\&$ Smith 2010). Exposure to animal species from other countries, that transported without veterinary care, can result in a major risk to human and livestock health, further impacting the broader economy by means of loss of productivity, food security and delays in the trade flow of every country [14].

East Asia was recognized as a major wildlife consumption hotspot and wildlife trafficking destination, grossing an estimated value of over US\$ 2.5 billion a year in illegal proceeds (UNODC 2013). While the majority of wildlife traditionally has been sourced

*Corresponding author: hanhtrangvnncs1@gmail.com 
locally, the increasing biodiversity depletion within the region and the trending demand for exotic species are driving a rapid growth in transcontinental wildlife trafficking, impacting ecosystems in upstream countries as ones in Africa[18].

In September 2016, the Instruction No.28/CT-TTg of Prime Minister was issued in order to implement urgent solutions for preventing and fighting the violation of wild animals. The Instruction stated that "Illegal activities, including processing, handicraft making and trading, and openly selling wildlife products such as ivory and rhino horns [were] still taking place" in the country. Signaling a tightening of the rule of law for wildlife protection, the government committed new energy to "monitor, investigate and apply stric punishment to those involved in illegal trade of ivory and rhino horn, as well as inspect craft villages, processing workshops, souvenir shops in tourist spots, airports, seaports, and traditional medicine shops".

In recent years, Viet Nam has implemented many programs in order to combat against wildlife crimes. The Criminal Code was revised in 2015 with higher punishment for wildlife crimes and two governmental decrees were updated (No. 06/2019/ND-CP and No. $64 / 2019 /$ ND-CP) with many more species enlisted in the list of protected species in Viet Nam.

As a result of management effort of the central government and provincial authorities, illegal wildlife hunting, transport and trade have been controlled, representing in the number of confiscated cases and prosecuations. However, only limited information is available about the actual magnitude of such trade in the country and on the performance of government agencies in enforcing wildlife protection regulations.

In this study, we review the status of wildlife criminal and administrative violation data during the period of 2013-2017. In addition, we discuss about challenges of prosecution and crimes relating to wildlife trade, with special focus on assessment of the impacts of wildlife tradecriminal to the biodiversity conservation and sustainable development in Viet Nam. Data was obtained from the Department of Criminal Justice Statistics and Information Technology, enforcement agencies (Public Security, Forest Protection, Customs, Border Guards), and the Procuracy departments at all level.

\section{Material and Methods}

The illegal wildlife trafficking poses a number of challenges when we were trying to estimate precise figures of the size of this trade. Assessments based on short-term illegal market surveys are only able to frame the emerging tip of such trade.

Basing on undercover investigations can provide deep insights into the trafficking practice, hunting and captivity, but are unlikely to offer a broad picture, besides the individual cases infiltrated. Therefore, data collected by the enforcement and specialized agencies in Viet Nam probably is the most reliable source to assess the actual magnitude of wildlife trafficking, and is the firm base of this review.

It shall be noted that collected data covered mainly closed cases, omitting an undefined number of pending cases for further investigation. Neither skills, equipment nor integrity variables were available and taken into account for this article.

Data of wildlife trade was reffered to the Review of wildlife violations and law enforcement response to wildlife offences in Viet Nam in 2013-2017 (WCS). This report was produced by the Wildlife Conservation Society (WCS) - Viet Nam Program in collaboration with the Supreme People's Procuracy of Viet Nam (the Department of Criminal Justice Statistics and Information Technology - Department 2), providing an assessement of the situation of wildlife violations and crimes between 2013 and 2017 through statistics and analysis of arrest and penalties for violations. The dataset used for this review consists of 1,504 cases, 1,461 violators handled by 315 units and law 
enforcement agencies across 56 centrally-administered provinces and cities, covering an area hosting $91.11 \%$ of the population in Viet Nam across the period of 2013-2017.

\section{Status on Wildlife Crimes in Viet Nam}

According to "The Review of wildlife violations and Law Enforcement Response to wildlife offences in Viet Nam in 2013-2017', a total of 1,504 violation cases with 1,461 violators of wildlife regulations were recorded in Viet Nam.

\subsection{Number of cases}

From 2013 to 2017, the enforcement agencies in Viet Nam detected and arrested 1,504 wildlife-related cases. Over 130 species were transported, traded, hunted and captivated illegally (Indicator: Proportion of trade by species (Crookes et al. 2005)), in which snakerelated cases topped the chart with $20.55 \%(309 / 1,504)$ of the case, followed by cases involving various types of turtle $10.31 \%(155 / 1,504)$, birds $8.58 \%(129 / 1,504)$, and pangolins $7.38 \%(111 / 1,504)$ (Indicator: Dominant species in the market (Dupain et al. 2012)). Elephants and rhinos accounted for a minimal share of the cases, respectively $3.39 \%(51 / 1,504)$ and $2.73 \%(41 / 1,504)$ of the total cases recorded during the 5 years of this review (Figure 1). It shall be noted that details of an unspecified number of trafficking cases involving species not native of Viet Nam were withheld from this review on the basis that the Penal Code 1999 did not include provisions about endangered non-native species. The reader is advised to exercise caution, as the actual share of elephant ivory and rhino horn trafficking in Viet Nam may not be accurately reflected in this analysis.

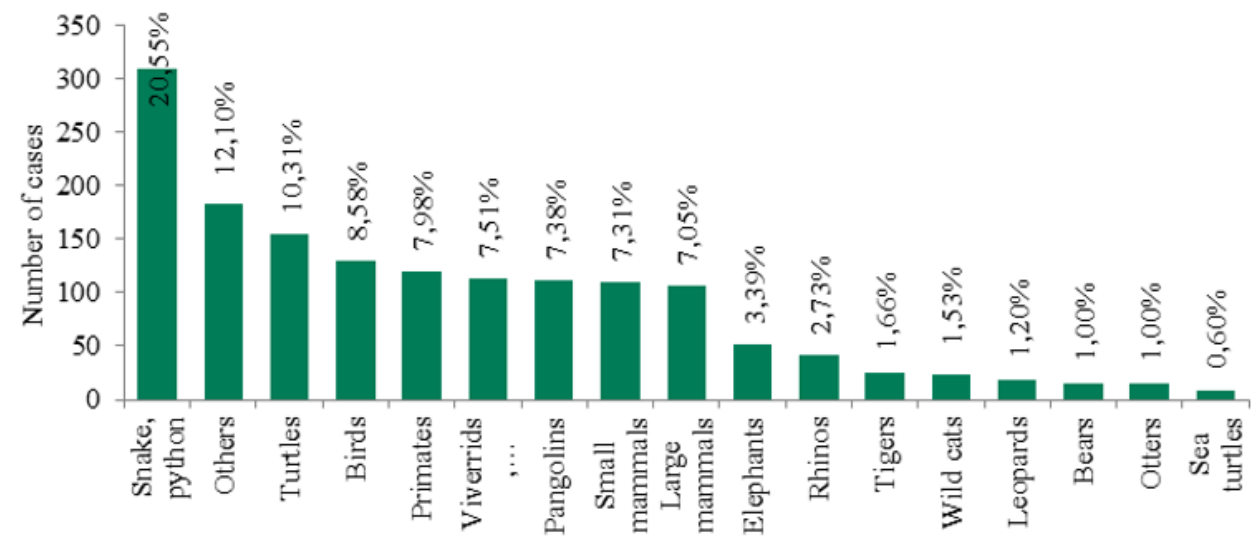

Fig. 1. Percentage of cases, in terms of wildlife species

\subsection{Seized species}

Out of more than 130 wildlife species that were illegally transported, traded, hunted and captivated as the number of animals confiscated indicated, turtles were by far the largest catch, accounting for nearly one-third $(31.23 \%$ or $8,118 / 26,221)$ of the total number of wildlife units confiscated, followed by birds $29.11 \%(7,632 / 26,221)$, snakes and boas $18.56 \%(4,867 / 26,221)$ and pangolins 7.43\% (1,949/26,221) (Figure 2) (Indicator: Number of trafficked wildlife (Weinbaum et al. 2013; CITES 2014; INTERPOL 2014; Milikem 2014; USFWS 2011; WCO 2007; WildAid 2014))

While this indicator can provide a solid representation of the number of traded birds, snakes 
and turtles, it falls short of identifying the actual trade magnitude in the case of wildlife products that can be fractionated such as scales of pangolin and ivories, hair and skin of elephants. Criteria for numbering the confiscated items varies broadly across the sample, which can be unit or weight, therefore this indicator shall be coupled with the confiscated weight volume in order to identify the species severely impacted by illegal wildlife hunting, transport, trafficking, captivating.

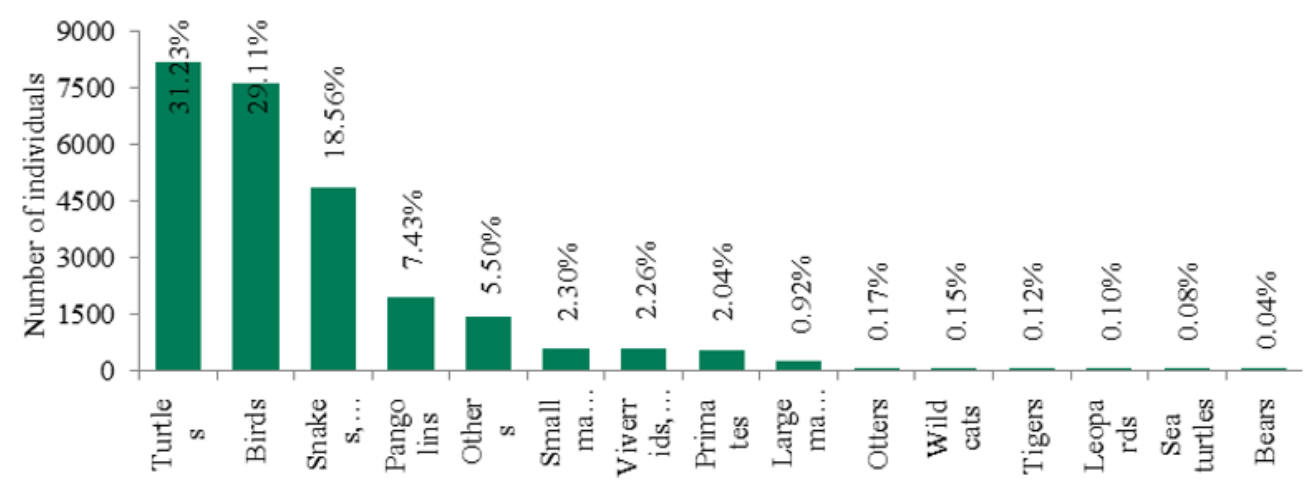

Fig. 2. Seized wildlife by units

Analyzing the total weight of confiscated species helps evaluate the wildlife trafficking (Indicator: Agnew et al. 2009; CI 2014; CI \& FAO 2002; CITES 2014; COMIFAC 2012; Crookes et al. 2005; DEFRA 2014; Dupain et al. 2012; GRASP 2014; Interpol 2013, 2014; Ntiamoa-Baide 1997; Sharma et al. 2014; TRAFFIC 2008; WCS 2014; WildAid 2014; Wingard \& Zahler 2006; WWF 2014; Zeller et al. 2011). Between January 2013 and December 2017, over 41 tons of wildlife and wildlife products were confiscated by law enforcement agencies in Viet Nam. This is a conservative figure given that the weight of the seizures was reported only in $71 \%$ of the cases. A majority of the volume recorded was the total weight of ivory, accounting for $23.55 \%(9,732 / 41,328 \mathrm{~kg})$; followed by pangolins $20.17 \%(8,337 / 41,328 \mathrm{~kg})$, and snakes and boas $16.69 \%(6,897 / 41,328 \mathrm{~kg})$. On the contrary, products from rhinos and birds were counted by number of units, making their total reported mass relatively minor: $0.92 \%(381 / 41,328 \mathrm{~kg})$ and $1.11 \%(459 / 41,328 \mathrm{~kg})$ respectively. See Figure 3 for detail numbers.

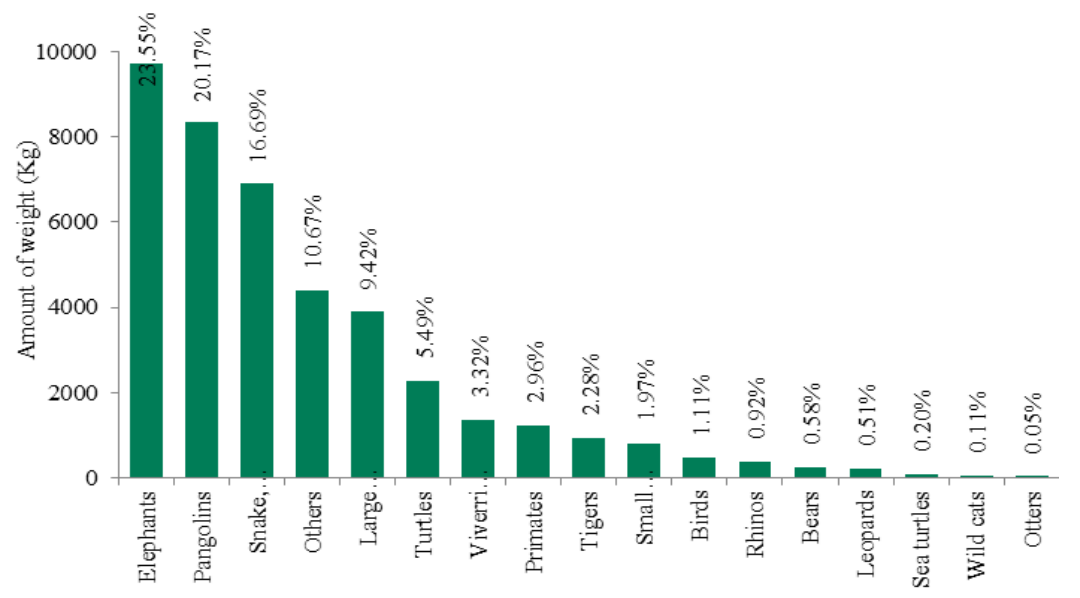

Fig. 3. Total weight of seized species 


\subsection{Types of seized animals}

Overall, 26,221 units and 41,328kg wildlife and products from wildlife were confiscated from January 2013 to December 2017. 80.13\% (21,011/26,221) of the units of wildlife were alive at the time of confiscation, $18.64 \%(4,887 / 26,221)$ were dead $(3,19 \%$ of the total weight, or $1,317 / 41,328 \mathrm{~kg}$ ), and the remaining - $1 \%$ of the units $(262 / 26,221)$ or $5.22 \%$ $(2,156 / 41,328 \mathrm{~kg}$ ) - were frozen (See Figure 4) (Indicators: Number of bodies confiscated and Number of alive confiscated (CITES 2014)).

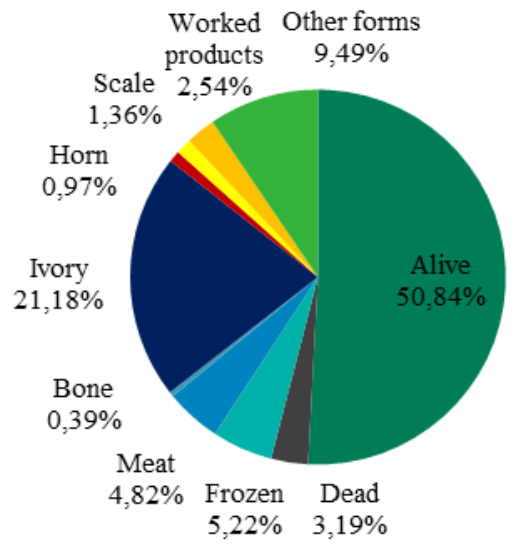

Fig. 4. Seized wildlife by weight

\subsection{Illegal Elephant Ivory trade}

From 2013 to 2017, the law enforcement agencies arrested and handled 48 cases in which elephant-related items confiscated weighed $9,732 \mathrm{~kg}$, accounting for the largest proportion of $23.55 \%$ (Figure 3 ).

The weight of raw ivory covered $89.95 \%(8,753 / 9,732 \mathrm{~kg})$ of the total weight of confiscated elephant-related items, the rest being such ivory products as rings and bracelets. Albeit large in number, such jewelry products have a limited weight, which explains why rings and bracelets combined accounted only for $10.04 \%(977 / 9,732 \mathrm{~kg})$ of the total weight of ivory confiscated - (Figure 6) (Indicators: Weight $(\mathrm{Kg})$ of ivory carvings and Quantity of ivory carvings (CITES 2014)).

From ivory seizure reports we can identify a majority of offenders $(43.75 \%)$ handling $20 \mathrm{~kg}$ to $150 \mathrm{~kg}$ of ivory (in 21 identified cases out of total 48 ) - an average level of violation. In addition, $22.92 \%(11 / 48)$ of the offenders handled as small-scale as $1 \mathrm{~kg}$ to $5 \mathrm{~kg}$. $25 \%(12 / 48)$ over $150 \mathrm{~kg}$. According to ICCWC, large-scale seizures are seizures of a size that is considered significant or unusual in its scale, implies the involvement of an organized criminal network, or that would be likely to have a significant impact on the species concerned. For ivory, a large-scale seizure is defined as a seizure of $500 \mathrm{Kg}$ or more (defined by CITES). For other species, a large-scale seizure may need to be defined on the basis of historical seizure data. Thereinafter, mentions of "large-scale" trafficking, seizures, or offenders in this review are solely estimation of WCS in comparison with illegal trade situation of each species. Remarkably, some offenders in Bạc Liêu Province traded 749 pieces of elephant ivory weighing 1,422kg (Figure 5).

Data collected was information on illegal ivory trade in only 10 municipalities in Viet Nam, which are Hà Nội, Hồ Chí Minh City, Lào Cai, Điện Biên, Bắc Giang, Quảng Ninh, Thanh Hóa, Nghệ An, Quảng Nam, Tây Ninh and Bạc Liêu (Figure 6). 


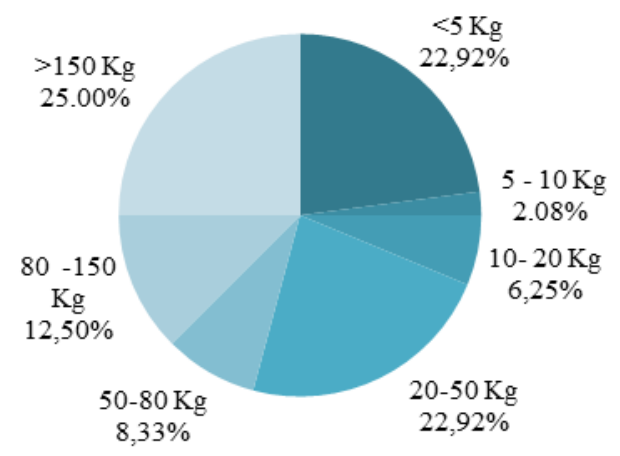

Fig. 5. Magnitude of ivory trafficking by weight

\subsection{Illegal Rhino Horn trade}

From 2013 to 2017, the law enforcement agencies dealt with 41 cases involving 228 rhino horns weighing $381.17 \mathrm{~kg}$. The seizures were carried out in 8 provinces and cities (Hà Nội, Quảng Ninh, Bắc Giang, Bắc Ninh, Thái Bình, Nghệ An, Tây Ninh and Hồ Chí Minh City). Hà Nội was the top province for seizures, totaling 130 horns weighing $195.8 \mathrm{~kg}$, followed by Hồ Chí Minh City with 68 horns (weighed $112.2 \mathrm{~kg}$ ), Nghệ An with $31 \mathrm{~kg}$ and Quảng Ninh with 4 horns (weighed 3.604kg) - the lowest (Figure 6).

Fig. 6. Geographical distribution of rhino seizures by weight 


\section{Discussion}

\subsection{Conservation impacts}

The International Union for Conservation of Nature (IUCN) defines conservation as the 'protection, care, management and maintenance of ecosystems, habitats, wildlife species and populations, within or outside of their natural environments, in order to safeguard the natural conditions for their long-term permanence.

Harvesting of wildlife for international trade can have positive and negative impacts on conservation. These largely depend on whether harvest is consistent with 'sustainable use', that is 'the use of components of biological diversity in a way and at a rate that does not lead to the long-term decline of biological diversity', and thereby maintains their contribution to present and future generations [1].

Negative impacts. Many species that collected for international trade, over-harvested, are extracted unsustainably (at rates faster than biological recovery). Overexploitation, (including for trade), is a major driver of global biodiversity decline, although habitat loss and invasive alien species generally pose much more significant threats [2]. Those species are common used by local people or international markets for consumptive use may be at greater risk of overexploitation [3-4]. While there do not appear to be any documented examples of species extinction driven by international trade, harvest for international trade (legal or illegal) has clearly led to the overexploitation of some species.

For example, there are many documented cases of trade in non-timber forest products (NTFP) leading to resource depletion [5-6].

Beyond the direct threat to species survival, overexploitation can indirectly affect ecological processes such as nutrient flows, pollination or seed dispersal. For example, harvest of mammals and birds for bushmeat depletes critical seed dispersers in forests in Asia and Africa, affecting future forest composition [7-8].

Furthermore, techniques and processes used in the harvest and management of wildlife species (such as strategies to intensify production) can contribute to habitat loss and degradation. Examples include the use of cyanide or dynamite to capture ornamental or food fish [9], or conversion of natural habitats to monoculture or other simplified farming systems. For instance, increased international demand for açai palm (Euterpe oleracea) in the Amazon has led to intensified production through enrichment of forests and, in some cases, thinning of competitors to plantation-like conditions [10].

Positive impacts. Wildlife harvest for trade can be maintained at sustainable levels, consistent with biodiversity conservation. Beyond this, however, wildlife trade can have positive conservation impacts where it creates incentives for sustainable use and management of target species and their habitats. For example, developing a well-managed international trade in vicuña (Vicugna vicugna) fibre has led many local communities to view vicuña as a valued resource rather than - as previously - a pest and competitor for grazing land. Consequently, poaching has declined and populations have recovered in many areas [11-12]. Legal and sustainable trade has successfully replaced illegal trade in the crocodile industry [13].

Similarly, for certain ornamental fish traded from Barcelos in the Brazilian Amazon, the benefits from trade have encouraged proper floodplain management and prevented destructive land-use change [14]. In such cases, species and habitat conservation outcomes are more favourable with trade than without it. A recent analysis found that utilized species are actually faring better than non-utilized species (e.g. food and raw materials) overall [15], providing some support for the widespread operation of these dynamics.

Bans on trade can be useful in some cases, such as to enable species to recover when stocks are depleted. But in other cases they can create adverse conservation incentives. For 
example, species may become undervalued and habitat converted to more productive uses, such as agriculture or plantation forestry. Alternatively, where species retain their market value, trade bans may stimulate illegal trade and excess harvesting.

\subsection{Criminal relating to wildlife in Viet Nam}

Recognizing the importance of biodiversity conservation, and the potential risks caused by the illegal trade and consumption of wildlife, Viet Nam has issued a number of policies and regulations to manage and protect rare species such as the Law on Forest Protection and Development (2004); the Fisheries and Biodiversity Act (2008); the Penal Code (1999, as amended in 2009 and 2015) [16]; Decree about the temporary regulations on hunting and catching birds and wildlife; Decree about the list of protected forest fauna and flora species; Decree about the management regime of rare and endangered species; and Decree about criteria to determine species and the regime of managing species under lists of endangered species prioritized protection. In 1994, Viet Nam joined the Convention on International Trade in Endangered Species of Wild Fauna and Flora (CITES) and a number of other international treaties on the protection of nature and biodiversity. These laws, policies, and regulations comprise Viet Nam's legal framework for the management and protection of wildlife species in a sustainable way. Along with laws, regulations, and international agreements to protect wildlife species, Viet Nam has established and developed more than 160 areas to protect its biodiversity and endangered species.

Laws and policies have not been developed and implemented consistently in Viet Nam, and sanctions imposed have not been an effective deterrence to such illegal acts as hunting, killing, captive breeding, transporting, and trafficking of wild animals. As demonstrated in this report, many cases relating to the illegal trade of wildlife have not been submitted to prosecutors, much less effectively prosecuted, investigated, nor promptly addressed, thereby not meeting the level of justice sector efforts needed to fight such crimes and to effectively protect rare and endangered wildlife species.

Disadvantages. Issues identified relating to cases violating laws and regulations on the protection of rare and endangered species for priority protection are as follows. For investigating and prosecuting criminal cases relating to wildlife trade, soliciting an expert examination at the local level is generally difficult. The case review found that, in most provinces and cities where the examinations were conducted, the local authorities had to call for examiners from Hanoi or Ho Chi Minh City. Many provinces and cities still do not have specialized expertise to examine violations relating to wildlife. The waiting periods for examinations significantly impact investigation deadlines.

In addition, after seizing wildlife, parts, or products, evidence must be preserved for examination to determine the correct species' names and protected categories. However, the competent authorities have inadequate funds for the preservation, care, and transfer of these species. Wildlife may be hybrids, which include species on the list of rare and endangered species, thus creating more difficulties for correctly identifying the species name and crime. Furthermore, the examination agencies that are often solicited for advice (such as the Institute of Ecology and Biological Resources of the Viet Nam Academy of Sciences and Technologies) are not those with the required expertise. Their examinations, therefore, are not reliable as a legal basis for decisions in criminal cases.

Regarding the management of live animals as physical evidence, the physical evidence is normally transferred to the agency responsible for preserving it. However, while waiting for the responsible agency to collect the physical evidence, there have been cases where animals have died due to prolonged time and insufficient procedures for transferring the wildlife. Local prosecutors have identified potentially effective practices for overcoming such difficulties, such as documenting the evidence early and then authorizing the release 
of the wildlife back into nature or to a rescue center.

Regarding the rescue and care for live protected animals, and preserving wildlife parts and products:

Wildlife on the list of rare and endangered species for priority protection normally require care prior to being released back into nature. However, there is no fund to care for these animals. Many provinces and cities do not have a rescue center for wildlife. Moreover, there is a lack of specialized equipment and infrastructure to save live animals. These issues are not easily addressed without increased funding and coordination to find effective, realistic solutions.

Regarding community awareness of laws on the protection of wildlife:

In reality, not all prosecutors, nor most persons, know which species are considered rare and endangered for priority protection. Especially in poorer provinces in border areas, the level of awareness and understanding of communities is very limited.

The detection, arrest, and management of offenders also poses many difficulties. Without strong community education and support for wildlife protection efforts, the public has limited awareness, and offers little support, for the detection of offenders and support to investigation and prosecution efforts.

Other difficulties and obstacles include:

- Overlapping legal provisions that create confusion on implementation

- Those directly involved in investigations and prosecutions are sometimes confused about appropriate processes for identifying and managing wildlife physical evidence. There are some emerging effective practices among local procuracies that are worth learning from.

- In some cases where parties are foreigners, it has been difficult to identify the subject or the ownership of cargo, or detecting the prohibited goods during shipment, as wildlife are often hidden carefully and skillfully. Processing cases with foreign elements is also difficult due to the long waiting period for responses from other countries for mutual legal assistance. In some cases, the responses to mutual legal assistance requests are never received. These challenges need to be studied further to identifying effective solutions.

Some possible causes of the challenges:

- Most people cannot distinguish which species should be protected, have limited (or no) understanding of the law, are unaware of when their own actions violate the law, or do not know which species are protected. For example, violations of the law include farming the green sea turtle, and buying and breeding otters as pets. Transporters are unaware that they are transporting prohibited species. Frequently, people do not understand the impact of the trade of some species, the huge profits gained from illegal trade, the impact of traditional beliefs that impact wildlife, or the impact of the organized criminal enterprises.

- There are others, however, who despite being aware of the importance of protecting rare and endangered species, still choose to violate the law for profit. For such persons, much stronger laws and penalties are necessary.

- Due to the influence of traditional culture and beliefs, many people, especially ethnic minorities, are still willing to use wildlife products for medicinal purposes (such as tiger bones and rhinoceros horn), which make it difficult for officials to explain and for local persons to understand the violation of the law. This can only be addressed through both improved enforcement and local education campaigns.

- The legal provisions on wildlife protection and management of criminal cases relating to wildlife are still incomplete. For instance, provisions on the management of live animals and the definition of animal parts and animal products in the 2015 Penal Code need further, detailed guidance to avoid confusion. 
- The number of crimes are still high due to profit-seeking and ignorance of the law, compounded by poor access to information on wildlife protection in general. This can be best addressed through increased transparency, public outreach by justice sector authorities, and improved community education.

- The economic benefits of the illegal wildlife trade is one of the key drivers of crimes. Most people know that they are breaking the law, but still commit offences because the benefits of the trade are lucrative.

- Coordination within the justice sector for detecting and managing wildlife crimes is still limited, and must be increased.

- The conditions of facilities and equipment to support the protection of wildlife, and the specialized competencies, qualifications, and skills of some justice sector agencies are still weak, and must be improved.

\section{Conclusion}

Based on the challenges and gaps identified from the case review, combined with suggestion the following recommendations are proposed:

Consolidation of the legal framework on wildlife prosecution

- Continue to improve the legal system with specific regulations and guidelines to manage criminal cases relating to wildlife. Supplement additional measures and more severe administrative punishments for violations involving even wildlife currently not on the list of criminal penalties. For example, increase fines and increase the number and species of animals. Also, increase the minimum criminal sentencing, and stipulate the confiscation and recovery of assets for offenses relating to wildlife to support the funding for wildlife protection.

- Assign further responsibilities and obligations to agencies assigned to manage live confiscated animals. If the animals die, specify the consequences the agencies would face. Clearly specify which specialized agencies have authority and the standardized procedures for managing wildlife physical evidence.

- Issue a valuation framework, and system of regular updates, for identifying the actual value of wildlife species.

Strengthen the prosecution process and protocol

- Provide documents to local investigators, as well as methods and guidance, to specifically support investigation and wildlife evidence management efforts.

- Investigate and conduct a survey to clarify the scale of criminal cases relating to wildlife nationwide to draw a clear picture of the situation, and to appraise good practices and recognize meaningful experiences in managing crimes relating to wildlife.

- Develop mechanisms for more frequent experience-sharing among local authorities managing criminal cases relating to wildlife. Also develop interdisciplinary training programs among investigators, namely the police, forest rangers, and customs, with procuracies and courts on managing criminal cases relating to wildlife.

- Organize hearings to draw experiences from notable criminal cases relating to wildlife. Continue to report to the justice sector on major cases relating to wildlife to share and improve prosecution success.

- Appoint more legal examiners specialized on the identification of endangered species to enable more effective and rapid examination of species, and to ensure the legality of the examination during investigation, prosecution, and trial, as well as during storage and management of physical evidence.

- Invest in facilities to preserve wildlife physical evidence, such as warehouses and cold 
rooms, among others. In addition, there should be documents outlining the coordination between agencies conducting legal proceedings, specialized biology agencies, and wildlife protection centers to quickly rescue live wildlife.

- Advance prosecutors' language skills and coordination with foreign partners for managing criminal cases relating to wildlife.

Improving the capacity of law enforcement forces and experience sharing:

- Strengthen the capacity of investigators in criminal cases in the areas of: laws and regulations relating to wildlife; criminal modus operandi; offenders' tricks and measures to evade detection; prevention; detecting signs of crime; and investigation skills. Methods for managing criminal cases relating to wildlife include: wildlife identification; crime scene examination; and collection and management of wildlife physical evidence, among other possible topics.

- Strengthen the capacity of law enforcement forces to manage criminal cases relating to wildlife, including equipping them with knowledge of wildlife species and identification, and prosecutorial techniques for complex crimes like wildlife trafficking.

- Provide clear guidance on the 2015 Penal Code and 2015 Criminal Procedure Code on crimes relating to wildlife to ensure that justice sector bodies have a shared understanding of the full reach and application of the laws. The improvements should include training programs for investigators, prosecutors, and judges on management of criminal cases relating to wildlife, focusing on: coordination; applying laws and regulations effectively to respond to complex crimes; identifying modus operandi; and documenting and managing wildlife physical evidence more properly and accountable.

- Share lessons learned from other countries on the detection, investigation, and prevention of criminal cases relating to wildlife.

- Develop training materials on investigation and prosecution of complex criminal cases like those relating to wildlife and organized criminal enterprises.

- Strengthen human resources, facilities, and financial support to procuracies to ensure that they have sufficient resources to improve international cooperation and to support the investigators, prosecution effort on transnational case and against criminal networks.

\section{References}

1. Secretariat of the Convention on Biological Diversity (CBD), Convention on Biological Diversity, (UN, 1992). Available from: https://www.cbd.int/doc/legal/cbd-en.pdf.

2. Secretariat of the Convention on Biological Diversity (CBD), Livelihood alternatives for the unsustainable use of bushmeat (Technical Series No. 60, 2011)

3. R.C. Kirkpatrick, L. Emerton, Conservation Biology, 24(3), 655-9 (2010). doi: 10.1111/j.1523-1739.2010.01468.x.

4. S.W. Purcell, B.A. Polidoro, J.-H. Hamel, R.U. Gamboa and A. Mercier, Proceedings of the Royal Society B. 281, (2014)

5. W. Darwall, K. Smith, D. Allen, M.B. Seddon, G. Reid, V. Clausnitzer and V. Kalkman, Wildlife in a Changing World - An Analysis of the 2008 IUCN Red List of Threatened Species, 43-54 (Gland, Switzerland, IUCN, 2009)

6. R. Neumann and E. Hirsch, Commercialisation of Non-Timber Forest Products: Review and Analysis of Research (Bogor, Indonesia, and Rome. CIFOR and FAO, 2000)

7. B. Belcher, M. Ruíz-Pérez and R. Achdiawan, World Development. 33(9), 1,435-1,452 (2005). 
8. E.O. Effiom, G. Nuñez-Iturri, H.G. Smith, U. Ottosson and O. Olsson. Proceedings of the Royal Society B: Biological Sciences 280(1759) (2013).

9. R.D. Harrison, S. Sylvester Tan, J.B. Plotkin, F. Slik, M. Detto, T. Brenes, A. Itoh and S.J. Davies. Ecology Letters 16(5), 687-694 (2013).

10. P. Mous, L. Pet-Soede, M. Eerdmann, H. Cesar, Y. Sadovy and J. Pet, Cyanide fishing on Indonesian coral reefs for the live food fish market: What is the problem? (Collected Essays on the Economics of Coral Reefs H. Cesar. Kalmar, Sweden: CORDIO, 69-76, (2000).

11. S. Weinstein, S. Moegenburg, Conservation and Society 2, 315-346, 2004)

12. R.R.J. McAllister, D. McNeill and I.J. Gordon. Journal of Environmental Management 90(1), 120-130 (2009).

13. G. Lichtenstein Journal of Latin American Geography. 12(1) 187-213,( 2013)

14. J.M. Hutton, G. Webb, Crocodiles: legal trade snaps back. The Trade in Wildlife: Regulation for Conservation, 108-120 (S. Oldfield, ed. London. Earthscan, 2003)

15. M.F. Tlusty, A.L. Rhyne, S. Dowd, L. Kaufman. Ornamental Fish International Journal. 75, 23-26, (2014)

16. M. Tierney, R.E.A. Almond, D. Stanwell-Smith, L. McRae, C. Zockler, B. Collen, M. Walpole, J. Hutton and S. De Bie, Oryx 48(3) 420-429 (2014)

17. Vietnamese National Assembly's, Amended 2015 Penal Code: Law number 100/2015/QH13 and number 12/2017/QH14 (Vietnam National Assembly Publisher, 2019)

18. The Supreme People's Procuracy of Viet Nam and the Department of Criminal Justice Statistics and Information Technology, The Review of wildlife violations and law enforcement response to wildlife offences in Viet Nam in 2013-2017 (WCS) (Judicial Publishing House, Hanoi, 2020). 